\title{
El oro o el agua, EL CASO del PÁramo de SANTURBáN
}

\author{
Gold or WATER, THE CASE OF THE PÁRAMo de SANTURBÁN
}

Dora María Cañón R.*

Yuly Alexandra Mojica R.**

Recibido: 18 de agosto de 2017

Aceptado: 14 de noviembre de 2017

\section{Resumen}

El artículo describe la situación del páramo de Santurbán tras la intervención de las compañías mineras y muestra su importancia como ecosistema estratégico y fuente de riqueza minera. Se identifican las causas que hacen atractivo al páramo para que se fortalezca allí la actividad minera, así como la consecuente destrucción del ecosistema y afectación de sus recursos. Igualmente, este estudio analiza los conflictos sociales en los municipios del área de influencia de Santurbán y resalta la confrontación entre el modelo de desarrollo del país basado en la minería a gran escala, la conservación de ecosistemas estratégicos, las comunidades que han optado por el agua antes que el oro y los pobladores que por tradición han sido mineros, actividad que es su único sustento y que ahora tiene un futuro incierto por el rumbo que está tomado el tema de la minería en Colombia.

Palabras clave: actividad minera, desarrollo sostenible, páramos, control social.

\begin{abstract}
The article describes the situation of the Páramo de Santurbán after the intervention of the mining companies and shows its importance as a strategic ecosystem and a source of mineral wealth. Identifying the causes that make it attractive to the Páramo to strengthen mining activity there, as well as the consequent destruction of the ecosystem and the impact of its resources. Likewise, this study analyzes the social conflicts in the municipalities in Santurbán's area of influence and highlights the confrontation between the country's development model based on large-scale mining, the conservation of strategic ecosystems, communities that have opted for water rather than gold and people who have traditionally been miners, an activity that is their only livelihood and which now has an uncertain future due to the direction that the mining issue in Colombia is taking.
\end{abstract}

Keywords: Mining activity, sustainable development, Páramos, social control.

\footnotetext{
* Ingeniera química, magíster, estudios de doctorado en Sostenibilidad. Docente investigadora, grupo de Investigación Gestión y Competitividad de las Organizaciones, línea de investigación Producción más Limpia, Fundación Universidad de América, Bogotá, Colombia. ORCID: http://orcid.org/0000-0002-9398-4808. dora.canon@investigadores.uamerica.edu.co ** Ingeniera de petróleos, especialista en Gestión Ambiental. yuly.a.mojica@gmail.com
} 


\section{INTRODUCCIÓN}

Las políticas formuladas en Colombia para incentivar el renglón mineroenergético, con las que se esperaba favorecer la explotación minera, no han sido suficientes para acelerar el sector, afectado especialmente por la drástica caída en los flujos de capital en el 2016 (Ahumada, 11 de mayo de 2017). Por su parte, los precios internacionales del carbón, oro y níquel se han incrementado y se espera un repunte de la inversión minera en producción para los próximos cinco años, que está condicionada a las garantías jurídicas que el país ofrezca frente a la seria problemática generada por las protestas cada día más sólidas y organizadas de la sociedad civil en contra de la minería. Debe recordarse que tanto la apertura a capitales extranjeros como el boom en los precios de las materias primas iniciado en el 2003, originados por una mayor demanda de los países asiáticos encabezados por China, favorecieron la inversión en la gran minería en territorio colombiano (Saade, 2014), lo que a su vez implicó la reacción de las comunidades ante la presencia de las compañías mineras en su territorio.

Para el sector minero la explotación del carbón representa el 2.2 \%; la de los minerales metálicos, el $0.7 \%$, y la de los minerales no metálicos, el 0.4 \% (CEPAL, 2014). En cuanto a inversión extranjera, Colombia ocupa el tercer lugar después de México y Perú (Saade, 2014). El país ha recibido importantes beneficios al incrementar sus ingresos fiscales como consecuencia de las ganancias e impuestos que percibe por las explotaciones mineras, principalmente a través de impuestos sobre la renta, impuestos al patrimonio, impuestos al valor agregado (IVA) y el cobro por regalías. Ahora bien, cabe preguntarse ¿el crecimiento económico favorecido por la actividad minera ha sido consecuente con la protección y conservación de los recursos naturales y con las comunidades que habitan las áreas de explotación?, ¿qué pasa con aquellos ecosistemas estratégicos intervenidos en aras de aumentar la producción minera?

Alrededor de las minas y sus procesos existe un complejo sistema social representado por los habitantes del territorio, la institucionalidad, los empleados de las empresas y los afectados por las operaciones de la actividad minera. Generalmente, en los territorios donde se localizan estas compañías se convive con otro tipo de actividades, como la agricultura, la pesca o la ganadería, que históricamente representan la fuente de sustento de las comunidades que han construido allí su territorio; los pobladores de los páramos, por ejemplo, vieron la transformación drástica de su territorio en los últimos sesenta años, lo que ha afectado su calidad de vida y deteriorado estos ecosistemas estratégicos (Instituto de Investigación de Recursos Biológicos Alexander von Humboldt, 2014).

La consulta y participación de las comunidades en cuestiones que afectan su territorio es un derecho reconocido por el Convenio 169 de la OIT:

Los pueblos interesados deberán tener el derecho de decidir sus propias prioridades en lo que atañe al proceso de desarrollo, en la medida en que éste afecte a sus vidas, creencias, instituciones y bienestar espiritual y a las tierras que ocupan o utilizan de alguna manera, y de controlar, en la medida de lo posible, su propio desarrollo económico, social y cultural. Además, dichos pueblos deberán participar en la formulación, aplicación y evaluación de los planes y programas de desarrollo nacional y regional susceptibles de afectarles directamente. (La Conferencia General de la Organización Internacional del Trabajo, 1989, art. 7, pár. 1)

Aunque el Convenio 169 es muy claro, en algunos casos no se ha consultado o invitado a las comunidades afectadas por los conflictos sociales generados entre las compañías mineras y los pobladores del páramo. Esto ha llevado a que en algunos casos se detenga la operación de los proyectos como La Colosa, operada por Anglo Gold Ashanti, compañía que en los últimos 14 años invirtió 
más 360 millones de dólares y que aún no ha podido iniciar actividades ("AngloGold Ashanti analizará", 27 de marzo de 2017).

La Corte Constitucional falló a favor de pobladores de Marmato y dio vía libre para que los mineros artesanales exploten la cima del cerro E1 Burro en tanto no se realice consulta previa ("Mineros artesanales", 28 de febrero de 2017). La empresa canadiense Gran Colombia Gold, con títulos en el área y afectada por el fallo, anunció una demanda por US $\$ 700$ millones. En este caso, el agua se antepuso al oro. Lo sucedido con el proyecto minero de La Colosa pone en riesgo los beneficios recibidos por la Nación y deja al país y a las empresas que quieren invertir en Colombia en un escenario de inseguridad jurídica por las diferencias entre el Gobierno nacional y las autoridades locales (Reuters, 25 de abril de 2017).

Por esta razón los proyectos mineros deben buscar una tabla de salvación que les brinde estabilidad jurídica y que a su vez involucre a las comunidades en toda la cadena. Al respecto, según la viceministra de Minas, María Isabel Ulloa (López, 2017), para lograr que tanto los proyectos mineros como las comunidades concreten los acuerdos, todos los actores sociales deben tener voz y ser escuchados.

Los conflictos producto de la presencia de compañías mineras en el territorio de los pobladores del páramo han llamado la atención de diferentes instancias sociales, entre ellas, la iglesia católica. Al respecto de la explotación de recursos naturales, la encíclica papal Laudato si' afirma.

Muchas formas altamente concentradas de explotación y degradación del medio ambiente no solo pueden acabar con los recursos de subsistencia locales, sino también con capacidades sociales que han permitido un modo de vida que durante mucho tiempo ha otorgado identidad cultural y un sentido de la existencia y de la convivencia. La desaparición de una cultura puede ser tanto o más grave que la desaparición de una especie animal o vegetal. La imposición de un estilo hegemónico de vida ligado a un modo de producción puede ser tan dañina como la alteración de los ecosistemas. (Francisco, 2015, cap. IV, p. 113).

La encíclica es un pronunciamiento sobre el tipo de relacionamiento entre actores sociales alrededor de un sistema económico de producción basado en los recursos naturales, en el que la existencia del ser humano es tan vital como la conservación de los recursos naturales.

El proceso minero demanda agua en cantidades significativas, lo que origina uno de los más serios conflictos ambientales y sociales, pues incide negativamente en las necesidades básicas de la población, como es el consumo en muchas ocasiones de aguas contaminadas con sustancias tóxicas. Por ejemplo, los resultados de la investigación adelantada por la Contraloría General de la República (Londoño, 6 de mayo de 2013) muestran que para la extracción de un gramo de oro se consumen hasta 1060 litros de agua; cuando esto sucede en los páramos la situación se vuelve mucho más crítica, pues estos ecosistemas son fuentes hídricas fundamentales. Para el Instituto von Humboldt (IAvH), la conservación de los páramos significa proteger cerca del $10 \%$ de la biodiversidad del país, así como conservar ecosistemas que "son los encargados de proveer alimentos y agua a un gran porcentaje de la población colombiana (IAvH, 2017, p. 9).

En los conflictos socioambientales, el papel de los principales actores involucrados (gobiernos, compañías mineras y comunidades del área de influencia) determina el tipo de oposición entre las empresas y las comunidades afectadas; al respecto, Saade (2014) afirma: "los conflictos han sido de dos tipos: a) entre las compañías mineras y las comunidades afectadas y b) entre niveles de Gobierno, especialmente entre el Gobierno central y autoridades locales" (p. 7). En el primer caso, las actividades mineras afectan seriamente los recursos naturales de uso común y alteran las dinámicas sociales y económicas propias del territorio, pues las grandes compañías intervienen el 
territorio sin concertación previa, violan derechos fundamentales y crean falsas expectativas sobre los programas de responsabilidad social corporativa.

Los aspectos socioambientales presentes en la relación minería, páramo y comunidades son la base de este artículo, en el que se plasman los resultados de la monografía De la actividad humana a los ecosistemas: el oro o el agua, caso del páramo de Santurbán (Mojina, 2017) y de la revisión de información pertinente. El caso de estudio sobre el páramo de Santurbán ayuda a describir lo sucedido con la intervención de compañías multinacionales y la participación social, y analiza la disyuntiva "conservación del agua" y "explotación del oro".

\section{EL PÁRAMO DE SANTURBÁN Y LA ACTIVIDAD MINERA}

El complejo del páramo de Santurbán abarca alrededor de 100000 hectáreas, se ubica entre los departamentos de Santander y Norte de Santander y entre otros servicios ecosistémicos, contribuye a la regulación hídrica y a la captación de carbono (Güiza, 2010).

Uno de los servicios ambientales más relevantes de Santurbán es el abastecimiento de agua de manera directa a los municipios bajo su jurisdicción y a la ciudad de Bucaramanga, además de servir a varios distritos de riego y a la termoeléctrica Termotasajero. Al igual que la mayoría de páramos del país, Santurbán cuenta cobertura vegetal natural y cobertura generada por la actividad humana (IAvH, 2017).

El páramo de Santurbán es considerado un complejo (Rangel e Instituto Alexander von Humboldt, citado en Morales, 2007). Abarca una amplia extensión de terreno en el que se encuentran diversos tipos de ecosistemas y cubre alrededor de 30 municipios. Este páramo está bajo la jurisdicción de tres corporaciones autónomas regionales, Corporación Autónoma Regional para la Defensa de la Meseta de Bucaramanga (CDMB), la Corporación Autónoma Regional de la Frontera Nororiental (CORPONOR) y la Corporación Autónoma de Santander (CAS). El municipio con mayor porcentaje de cobertura superficial dentro del páramo es Vetas (75.90\%) (Sarmiento, 2014).

Con el paso del tiempo y el crecimiento demográfico, los espacios rurales son más vulnerables a los impactos ambientales negativos, como la expansión poblacional, actividades productivas, explotación minera o gestión descontrolada de los proyectos de explotación de oro, que pueden desatar un grave problema de contaminación en las fuentes hídricas del páramo (Agence Française de Développement, 2014).

Algunas de las grandes empresas mineras prometen riqueza y empleo, al tiempo que llevan a la destrucción de las formas de sustento y de vida de las comunidades y al desplazamiento de las actividades económicas locales actuales y/o futuras (Duque, 2011). Los habitantes de los páramos son directamente afectados por la destrucción ambiental de estos ecosistemas, por lo tanto deberían ser escuchados acerca del uso adecuado los recursos del páramo y aplicar sus saberes y conocimientos.

Según CORPONOR y la CDMB (citado en Morales, 2007), en el páramo de Santurbán los campesinos practican la minería a pequeña escala, mientras que el Estado promueve la gran minería. El distrito minero reconocido del complejo paramuno está localizado en los municipios de California y Vetas, en el que se han adelantado actividades de exploración y explotación; este distrito es considerado una de las principales fuentes económicas del departamento de Santander por las propiedades de su suelo, que tiene una riqueza predominante de filones de oro y plata, asociados con sulfuros de hierro, plomo, zinc, cobre y sulfosales o minerales de azufre no oxidado.

Los sistemas de producción minera se han llevado a cabo de manera intensiva y extensiva en el páramo; esta actividad ha facilitado la supervivencia de la población cercana al distrito minero. Para que la actividad genere mayores ingresos económicos, es necesario un uso intensivo del suelo, 
lo que puede resultar en una interrupción de los procesos naturales del ecosistema y afectar la regeneración vegetal de la zona (López y Díaz, 2009).

Teniendo en cuenta lo presentado por García (2013), la razón por la cual la actividad minera tiene este comportamiento es que, además de la inversión extranjera en el distrito aurífero de California-Vetas (impulsada por el alza en los precios de los metales), los habitantes de páramo (en su mayoría población rural y comunidad campesina) ven más viable dedicarse a estas actividades extractivas que tienen un mayor beneficio económico. La minería artesanal difiere de la gran escala en que esta comprende asociaciones familiares que contratan en promedio a veinte obreros en sus labores y complementan la actividad con agricultura, entre otros trabajos, mientras que la de gran escala incluye grandes predios, maquinaria y más tecnología (Buitrago, 2012).

La explotación minera a gran escala no representa por sí misma un peligro para el escenario natural donde se desarrolla, lo crítico está en la forma como se adelanta esa actividad, en la eficiencia de las medidas aplicadas para mitigar o reducir posibles impactos ambientales y socioeconómicos y en la responsabilidad social y ambiental de las empresas para relacionarse con los diferentes actores sociales.

De acuerdo con el informe de García (2013), cada uno de los ocho predios analizados en su estudio extrae aproximadamente 17 gramos de oro al día y 1.2 gramos diarios por hectárea, logrando unas ventas anuales para los ocho predios de $16.2 \mathrm{Kg}$ anuales, que generan un ingreso de $\$ 1735000000$ (en esta actividad participan en promedio 603 jornaleros). El estudio describe al páramo de Santurbán como una fuente de riqueza minera que promete ingresos por encima de las demás actividades económicas, incluso cuenta con una diferencia de alrededor de $\$ 48875000$ pesos colombianos, con ganancias superiores a la pecuaria (que es la siguiente actividad más rentable y que promete ingresos de hasta $\$ 168000000$ al año, estando en sus condiciones más favorables, mientras que la minería alcanza valores de $\$ 400000000$ en condiciones de ingresos máximos en el distrito minero de California-Vetas). Pero ¿el oro, el salario y las regalías justifican la pérdida de especies naturales, la degradación del suelo, el agua, el aire, la modificación drástica del paisaje?, ¿los resultados económicos justifican el deterioro ambiental y la pérdida de la piel de nuestra tierra?, ¿qué es más valioso, el oro o el agua?

Eco Oro (antes denominada Greystar) es la empresa multinacional con mayor número de hectáreas tituladas en la zona, por lo que es la empresa de mayor influencia ("El fracaso de Santurbán”, 9 de abril de 2016). Su proyecto de mayor envergadura a nivel económico es el de Angostura; sin embargo, se considera que este proyecto tiene el mayor y más grave impacto socioambiental sobre el ecosistema de páramo y las comunidades, razón por la que le fue negada su licencia ambiental (Alzate, 2015).

El proyecto Angostura generó polémica entre comunidades, autoridades ambientales y otros sectores por la magnitud del proyecto y los graves impactos socioambientales que implicaba. Se proponía la extracción de oro a cielo abierto con una fosa de profundidad máxima $400 \mathrm{~m}$, una longitud de $2 \mathrm{~km}$ y un ancho de $1.2 \mathrm{~km}$; por su parte, el material extraído de poca relevancia para la actividad minera sería dispuesto directamente en escombreras y la roca mineralizada molida para ser lixiviada con cianuro (Fierro, 2011). La empresa finalmente decidió retirar la solicitud de licencia técnica y ambiental luego de los conflictos que generaba el desarrollo de la minería en los páramos.

Entre los proyectos mineros desarrollados o propuestos en la actualidad y que están localizados en Santurbán y dentro del distrito de Vetas y California (información tomada de Red Eagle Exploration, 2017) se encuentran: Angostura, ${ }^{1}$ Minesa, Galway, Vetas Gold, California, La Bodega/

\footnotetext{
${ }^{1}$ Este proyecto fue modificado por Eco Oro y propone desarrollarse de manera subterránea (Eco Oro minerals Corp., 2017).
} 
La Mascota. Las reservas de oro más prometedores son las de La Bodega/La Mascota, con 3.5 millones de onzas (Red Eagle Exploration, 2017).

\section{La gran controversia: comunidades y su vínculo con la minería}

Buitrago (2012) determinó en su estudio que los municipios mineros por excelencia son California y Vetas, vecinos y parte del complejo de páramo de Santurbán. Estos municipios han sido distritos mineros desde antes de la llegada de Greystar (Eco Oro). La zona fue habitaba por indígenas dedicados al barequeo y la extracción de oro en río, donde trituraban la roca para conseguir el mineral, técnica que fue adoptada posteriormente por los campesinos.

Según cifras de la alcaldía municipal de Vetas del 2016, en el municipio habitan 1962 personas, de las cuales 1109 están en condiciones de trabajar. La minería formal solo genera 250 empleos y los cerca de 100 comerciantes del pueblo no alcanzan a ocupar toda la fuerza laboral ("El fracaso de Santurbán”, 9 de abril de 2016). El desempleo se encuentra alrededor del 70 \%; con el fallo de la Corte Constitucional en contra de la actividad minera en el páramo (Sentencias C-035 de 2016), este valor puede aumentar drásticamente. Esto afecta a las comunidades que dependen completamente de la explotación minera porque de ahí devengan su salario y, por lo tanto, esta es la única forma de subsistencia.

En Vetas, la incertidumbre de los campesinos crece ante el fallo de la Corte. Según Orlando Rodríguez, alcalde de Vetas: "va a ser una catástrofe porque ya nadie va a poder trabajar. La Corte no tuvo en cuenta que en este pueblo dependemos totalmente de la minería" ("El fracaso de Santurbán”, 9 de abril de 2016).

Buitrago (2012) realizó una indagación etnográfica con los pobladores de los municipios, con la que determinó que la población está conformada por campesinos, pequeños mineros, obreros de multinacionales, líderes comunitarios y entidades locales y regionales de carácter ambiental. Según este estudio, los grupos más representativos de Santurbán son los guardianes del páramo, cuyos intereses se centran en la protección del recurso hídrico, y las pequeñas asociaciones de mineros, cuyos modos de subsistencia están basados en la minería desde hace más de un siglo.

En lo relacionado con la extracción de oro, la oferta de empleo es el factor que vincula a las comunidades campesinas con las multinacionales del sector minero. La oportunidad laboral que ofrece la minería se divide en dos opciones: la minería artesanal, realizada por los campesinos y pequeños mineros en sus predios, y las multinacionales, que ofrecen empleos para la población en el área de influencia de sus proyectos (Centro de Investigación y Educación Popular, 2012).

La controversia está en que estas decisiones trascendentales para la conservación de los ecosistemas paramunos no fueron consultadas con las poblaciones localizadas históricamente en estos sitios. En este sentido, José Alfonso Rodríguez, minero entrevistado por la revista Semana, afirma: "Por eso sentimos que la Corte está cometiendo una injusticia, tomaron la decisión desde Bogotá. Nunca vinieron acá a mirar cómo hacemos nosotros la minería y la problemática que generan si nos la prohíben" ("El fracaso de Santurbán”, 9 de abril de 2016).

Hablar de páramos es evocar inmediatamente el origen del agua, los colchones saturados de ese precioso líquido, es traer a la mente las lagunas, los frailejones; pero también implica reconocer a más de 2000 familias que viven de la agricultura y la minería, quienes crearon su propio territorio y que ya son parte de él. De ahí lo complejo que resulta delimitar un páramo, pues se puede desconocer los procesos sociales y económicos que ocurren en el interior de este sistema estratégico y biodiverso.

Para IAvH (s. f.), la delimitación de los páramos implica la definición de "complejo" de ecosistemas de páramos y alta montaña en general, como criterio mínimo y fundamental para su protección: 
Se considera que una intervención de los ecosistemas de alta montaña, ocasionada por minería a cielo abierto de la magnitud solicitada, irá en detrimento de dicha función, con poca o ninguna garantía de restauración de su funcionalidad, aún en el mediano o largo plazo, dadas las limitaciones biofísicas para la formación de suelos orgánicos y comunidades vegetales propias del páramo, las cuales están estrechamente vinculadas a la regulación natural del recurso hídrico. (p. 22)

Cabe resaltar que el $70 \%$ de las empresas hoy legalizadas en el municipio de Vetas y localizadas sobre zonas de páramo forman parte del programa de legalización de minería de hecho desarrollado por el Ingeominas, la UIS y la CDMB (IAvH, s.f.).

Según el Centro de Investigación y Educación Popular (2012), se generan ciertos conflictos que ponen en situación de vulnerabilidad a la comunidad campesina habitante del páramo. Al ser el oro un mineral atractivo para las multinacionales, los predios de la población rural son comprados para destinarlos a la actividad de estas compañías, eliminando así la fuente principal de ingresos de muchas familias; por otra parte, no obstante los campesinos cuenten con sus propios predios, la legislación Colombiana no permite practicar minería ni agricultura tradicional en la zona del ecosistema estratégico.

Los conflictos entre las comunidades y las empresas mineras se asocian a aspectos laborales y de ordenamiento territorial y ambiental que afectan directamente el uso de los recursos naturales y la calidad de vida de los habitantes. En la figura 1 se esquematizan las principales razones y temas de discordia entre las partes; la que mayor preocupación genera es el incumplimiento de pactos, con un $24 \%$, seguida por la lucha en defensa de los derechos sociales y protección del ambiente, con $16 \%$ y $14 \%$, respectivamente.

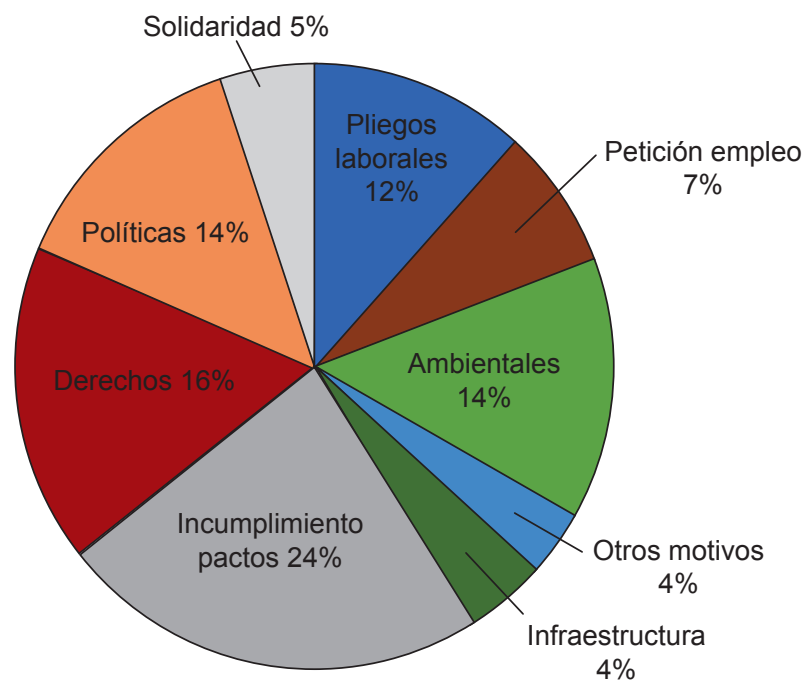

Figura 1. Motivos de lucha de las comunidades frente a la extracción de petróleo, oro y carbón.

Fuente: Centro de Investigación y Educación Popular (2012).

\section{Impacto de la minería en la comunidad de Santurbán}

En los municipios de Vetas y California, la población campesina de tradición minera busca el beneficio económico y el bienestar social en las grandes empresas (Duque, 2011). Algunas de las razones que motivan la aceptación de los habitantes locales para adelantar actividades mineras son: 
- Desconocimiento sobre los impactos que genera la actividad en el ecosistema.

- Dependencia y búsqueda del beneficio económico para asegurar calidad de vida en la población.

- Promesas de empleo.

- Vulnerabilidad de la comunidad.

Una vez se acepta por consenso local la entrada de operaciones de las compañías mineras, los pobladores encuentran:

- Bajo desarrollo regional del distrito.

- Reemplazo de las economías locales.

- Entrega de los predios a las grandes multinacionales y la ilegalidad.

Para Buitrago (2012), la minería puede causar impresiones favorables y desfavorables en las comunidades; por un lado, generan aceptación en la población que depende de estas actividades y que de cierta forma se ve beneficiada por los programas de responsabilidad social de las empresas; por el otro, se encuentra la comunidad que está en contra de los proyectos mineros, que defiende la integridad del ecosistema y de los servicios ambientales que presta.

Aunque los hechos ponen en tela de juicio ambas partes del conflicto, por un lado, se encuentran la organizaciones a favor de la protección del ambiente y la sociedad ambientalista, y, por otro, el municipio de Vetas, que está preocupado por la actividad que sustenta su día a día.

Según la investigación de Semana ("El fracaso de Santurbán”, 2016), los cerca de dos mil habitantes del municipio de Vetas temen que el fallo de la Corte los obligue a dejar la minería, actividad que han practicado desde hace más de cien de años y que es su principal fuente de sustento. Además, hay que tener en cuenta que parte de su casco urbano y entrada a las minas se encuentran dentro de área delimitada para la protección del páramo. Detrás de la lucha por la protección del complejo de páramo de Santurbán, se encuentran los mineros tradicionales, quienes aseguran que el municipio y sus familias dependen del oro y que la prohibición de esta práctica podría dejarlos sin sustento. Aquí surge la controversia entre la conservación y protección de ecosistemas altamente vulnerables y los pequeños mineros de tradición que quedan desempleados y sin proyecciones futuras.

El mapa realizado en 2014 por el IAvH delimitó este territorio en un área de referencia de 129000 hectáreas, en las que las condiciones biológicas y físicas de altitud, tipo de vegetación, suelos y temperatura establecían un ecosistema de páramo que debía ser protegido. Sin embargo, en la cartografía realizada no estaban representadas las características socioeconómicas del lugar; así, mientras que en el municipio de California algunos de los proyectos siguieron siendo viables, pues solo debían trasladarse un poco, en Vetas se prohibió la única actividad económica que los ha mantenido por años.

Tanto el agua como el oro son los dos recursos configuradores principales del paisaje y el territorio en los municipios de Vetas y California; el primero, recurso indispensable para la vida y la producción, y el segundo, principal ordenador de los modos de producción y sustento económico.

Con la llegada de las multinacionales, las transformaciones se presentaron principalmente en las prácticas culturales, lo que también significa transformaciones en el territorio. Los ritmos de vida y, en especial, de trabajo son los aspectos más afectados. Los tiempos de trabajo, la disminución de los cultivos (tanto en espacio, como en personal), la consecuente llegada de camiones, la negativa de las multinacionales a contratar mujeres para el barequeo, el aumento de seguridad en las minas y la invasión en las minas artesanales de los municipios son los aspectos más representativos de los cambios que ha sufrido la cultura de Vetas y California y frente a las cuales la comunidad no ha pensado en otra opción que la resignación (Buitrago, 2012). 


\section{Impactos desfavorables sobre el medio natural y los recursos del páramo de Santurbán}

La minería en zonas de páramo empezó a generar una serie de impactos negativos sobre el ambiente, pues su ritmo de producción conlleva graves e irreparables consecuencias. Según Duque (2011), entre estos impactos se encuentra: la modificación de la topografía y el paisaje; la alteración del carácter físico, fisicoquímico y químico en suelo y subsuelo; la infertilidad y el paso de contaminantes a través del agua debido a la remoción superficial del suelo y materiales de cobertura; la generación de taludes que modifican drásticamente las formas y las pendientes naturales de las laderas por donde fluyen los cauces de agua; el cambio en el comportamiento mecánico del suelo (lo que evita la formación y acumulación de materia orgánica); la producción de contaminantes gaseosos, líquidos y sólidos que de forma directa o indirecta recibirá el suelo; la alteración de la capacidad de regulación hídrica y la pérdida irreversible de la función del soporte físico de ecosistemas; la disminución de los caudales, lo que altera el sistema de drenaje natural; la interrupción del nivel freático y los ciclos hidrológicos; la alteración del curso de los caudales; el cambio de los hábitats naturales de la fauna y la flora; la alteración de la dinámica de las cadenas tróficas, entre otros.

Para García (2013), la extracción de 1.1 gramos de oro por hectárea en promedio es una cantidad muy baja de oro frente a la extensión de terreno que debe utilizarse para tal actividad. En la minería de extracción de oro, según proyecciones de la Contraloría General de la Nación (2017), la cantidad de residuos generados tras la actividad se encontrarían alrededor de 4300 millones de toneladas de escombros durante un periodo menor a treinta años. Igualmente, la actividad minera y las excavaciones liberan sustancias químicas tóxicas, como el arsénico, que pueden contaminar las fuentes hídricas (Cabrera y Fierro, 2013). Los residuos pueden generar también sedimentación en ríos por el vertimiento de los mismos a las fuentes hídricas, la contaminación por la liberación de sustancias tóxicas, entre otros factores, que además de perjudicar al medio, también provoca afectaciones a la salud humana.

El estudio realizado por Tapia (citado en Cabrera y Fierro, 2013) determinó que para una extracción promedio de 0.94 gramos por tonelada de oro extraído se emplean entre 0.5 a $1 \mathrm{~m}^{3} \mathrm{de}$ agua por tonelada de material procesado; lo que significa que se requieren de 530 a 1060 litros de agua por gramo de oro, esto teniendo en cuenta que el agua en cuestión está involucrada en la demanda de uso de los proyectos, mas no la empleada para aprovechamiento y/o el agua contaminada por los procesos.

\section{Acciones tomadas por las autoridades y la comunidad en Santurbán}

A pesar del fallo emitido por la Corte en 2016, en cuanto a la prohibición de esta actividad en las zonas delimitadas de páramo, el sector minero es bastante fuerte (Contraloría General de la República de Colombia, 9 de febrero de 2017). Según el informe de la Contraloría, esta situación provocaría acciones disciplinarias de las autoridades ambientales responsables, como Corponor y Agencia Nacional de Licencias Ambientales (ANLA), principalmente.

Según los informes de la Contraloría, las corporaciones autónomas regionales con jurisdicción en el área del páramo de Santurbán no adelantaron las acciones administrativas necesarias para hacer cumplir la decisión de las Corte en la delimitación y exclusión de la minería en el páramo (se afirma que el Ministerio de Ambiente ha sido permisivo frente a los incumplimientos).

Según el mismo informe de la Contraloría, los resultados estimados muestran que el $71.48 \%$ de las superficies de ecosistemas de páramo aún no están delimitadas y que el $60.45 \%$ de esas superficies corresponde a áreas desprotegidas. Se observa también la dualidad de los habitantes, unos en contra y otros a favor de la minería. En el primer caso se encuentra el Comité para la Defensa del Agua y 
del Páramo de Santurbán, que hace algunos años ha demandado las actividades de las empresas en la zona de páramo, y cuya preocupación actual es la negociación de la Sociedad Minera de Santander para poner en marcha un proyecto extractivista que, según afirma, no se encuentra dentro del límite de páramo y será puesto en marcha de manera subterránea; esto, sin embargo, alerta al Comité, ya que los túneles podrían llegar a afectar el ecosistema (Monsalve, 2017).

Otra de las preocupaciones del Comité es la falta de independencia de las autoridades ambientales ante los convenios firmados por la Asociación Minera con la Corporación Autónoma Regional para la Meseta de Bucaramanga; no obstante, esta asociación llegó a un acuerdo para promover estrategias de sostenibilidad en la cuenca, además de planes para mejorar la operación de las plantas de tratamiento de aguas residuales de algunos municipios aledaños. A la fecha, al igual que hace unos años con la polémica de Angostura, se están empezando a hacer plantones como medida de resistencia ante la minería en la zona (Monsalve, 2017).

\section{LAS EMPRESAS MINERAS Y SU REALIDAD}

Un actor significativo que no puede dejarse de lado en este análisis es la compañía minera y sus horizontes en cuanto las inversiones necesarias para asegurar rentabilidad del proyecto y las relaciones con comunidades vecinas.

Los resultados de la brújula minera ${ }^{2}$ muestran como la imagen de las empresas mineras en los municipios es negativa; solo el $46 \%$ tiene una imagen positiva frente a el $52 \%$ de imagen negativa (Cuestas, 2015, p. 14). Ante la pregunta “¿qué pasa si en un municipio minero desaparece esta actividad?", el $40 \%$ de los habitantes de los municipios mineros y del $31 \%$ de quienes no viven en esas zonas respondió que la calidad de vida en los municipios sería peor si las empresas mineras dejaran de operar (el $30 \%$ considera que las cosas seguirían igual).

Este análisis debe incluir la poca acción del Estado contra la minería ilegal, que se ha extendido por distintas regiones del país y cuyos efectos sociales son devastadores, pues propaga la violencia, estimula la economía ilegal y financia organizaciones al margen de la ley.

Desafortunadamente, la minería ilegal agrupa centenares de campesinos sin vocería ni liderazgo social, quienes ven en este tipo de actividad la única forma de supervivencia económica, a pesar de los riesgos presentes. Es un problema social porque exige mayor presencia del Estado y de la fuerza pública, debido a que en áreas de minería ilegal conviven los actores armados con los campesinos.

¿Cuál es el futuro de las compañías mineras? La encuesta abordó este interrogante entre los principales empresarios del sector, a los que se les preguntó: ¿usted cree que en los próximos cinco años las empresas mineras expandirán, reducirán o mantendrá igual sus operaciones? El $62 \%$ de los directivos creen que sus empresas podrán expandir su operación en el próximo lustro, mientras que el $13 \%$ respondieron que se mantendrá igual, o sea, tres de cada cuatro directivos confían en el crecimiento o estabilidad de la actividad minera.

Para completar el análisis, se preguntó a los directivos sobre cuál consideraban era el principal problema ambiental de la minería en Colombia: el $23 \%$ consideró que era la minería ilegal; el $16 \%$, la falta de claridad en las normas y políticas, y el $15 \%$, la falta de comunicación oportuna y la consecuente desinformación.

Para atenuar la mala reputación de las compañías mineras, cuestión que afecta la continuidad de los proyectos y las nuevas inversiones, las compañías más importantes a nivel mundial lanzaron la Iniciativa de Minería Global para establecer un vínculo positivo entre minería y desarrollo

${ }^{2}$ Es una herramienta de evaluación y seguimiento de la minería en todo el país, consolidada por el Centro Nacional de Consultoría (CNC) y Mundo Minero. 
sustentable. De esta iniciativa surgió el Proyecto de Minería, Minerales y Desarrollo Sostenible (MMSD), siendo uno de los pilares para la implementación de buenas prácticas de la industria minera. Se habla de la gestión de valor de la minería, porque aborda todos los escenarios posibles de impactos a nivel cultural, psicológico y ambiental, además de los financieros y económicos. Para evaluar los impactos directos e indirectos que van más allá de lo que implican las actividades del sector minero, se estableció que el valor creado para la minería considera tanto beneficios como costos e involucra las compras y cadena de suministro local, por lo que se habla de stakeholder y la generación de valor para todos (World Economic Forum, 2013).

Con el fin de restablecer la confianza en la minería, las compañías deben mejorar la comunicación con las comunidades afectadas. Muchas empresas mineras están aplicando buenas prácticas, que incluyen involucrar a las comunidades afectadas de una manera más activa en la toma de decisiones, tanto en la etapa previa al inicio de los proyectos, como durante el desarrollo de los mismos, e incluso en la etapa post-cierre (Saade, 2014, p.33).

Anualmente, el Instituto Fraser $^{3}$ realiza una encuesta para alertar si las provincias, estados o países mineros están llevando a cabo buenas prácticas mineras. Este es un medio para obtener los índices y evaluar la riqueza mineral y las políticas públicas que pueden promover o desalentar nuevas inversiones mineras. Se busca encontrar factores de política influyentes en este sector, como: la inseguridad ante las regulaciones administrativas y ambientales, el sistema legal y el régimen tributario, la incertidumbre relacionada con las áreas protegidas y los reclamos territoriales, la infraestructura, el desarrollo socioeconómico de las condiciones de las comunidades, las barreras al comercio, la estabilidad política, las regulaciones laborales, la calidad de la base de datos geológica, la seguridad, la oferta laboral capacitada, la corrupción y la incertidumbre (Sociedad Nacional de Minería, Petróleo y Energía, 2017).

Según este índice, Colombia descendió del puesto 34 en el 2011 al 55 en el 2015 en el escalafón de nivel de atracción de inversión entre 109 países y territorios mineros. Esto se debe a que las empresas del sector a nivel mundial perciben en el país políticas poco claras, no bien aplicadas y cambiantes, lo que genera incertidumbre para la inversión ("Cambio de reglas", 30 de marzo de 2016).

Los analistas coinciden en que el principal reto para la formulación de las políticas, tanto en Colombia como en los demás países, es estructurar regulaciones duraderas y claras que sean expuestas de igual forma a los inversionistas y público en general. Al respecto, Fred McMahon, investigador del instituto Fraser, ${ }^{4}$ afirma:

Lo que las compañías mineras quieren es certidumbre, entienden la necesidad de regulación, de proteger el medioambiente y de pagar impuestos. Países como Suecia, Finlandia, Noruega y Canadá, en donde existen bastantes regulaciones, altos impuestos y una gran protección ambiental, figuran entre los mejores para atraer inversión en minería. ("Cambio de reglas", 30 de marzo de 2016)

Sobre las reglas ambientales, McMahon considera que el ambiente político y los intereses propios de las regiones están por encima de lo ambiental, sin que exista un rumbo claro, aun en el futuro inmediato.

\footnotetext{
${ }^{3}$ El instituto Fraser (www.fraserinstitute.org) es una organización canadiense independiente que realiza investigaciones sobre temas económicos, sociales y educativos. Su objetivo es que el público en general tenga un mayor conocimiento sobre el papel que tienen los mercados competitivos en el bienestar económico y social. También realiza investigaciones de sectores donde están relacionadas empresas canadienses, como el Reporte Anual de Compañías Mineras, con el que se busca comparar las realidades geológicas y regulatorias sobre el aprovechamiento del recurso minero en varios países.

${ }^{4}$ Investigador del instituto Fraser encargado de coordinar la encuesta minera desde el 2003 hasta el 2013.
} 
Los directivos del sector se quejan de tres situaciones: a) inseguridad jurídica de la propiedad de un bien determinado; b) cambios en las condiciones y requisitos con que fueron otorgados los permisos ambientales y sin que medie razón alguna que defienda lo ya aprobado; c) largos períodos de aprobación en los permisos de perforación.

\section{Conclusiones}

El páramo de Santurbán es una fuente de riqueza hídrica para los municipios bajo su jurisdicción, así como sus formaciones rocosas son un atractivo para la inversión y la llegada de multinacionales mineras. En esta zona existe la confrontación entre desarrollo y tradición: por un lado está el oro, que ha acompañado por años la tradición minera de los campesinos colombianos, y por el otro, el modelo de desarrollo económico del país, basado en la explotación de los recursos del suelo y subsuelo colombiano. El punto de quiebre es la presencia de multinacionales interesadas en invertir en Colombia para extraer minerales en áreas que corresponden a ecosistemas estratégicos, como los páramos. Sin embargo, no es posible desconocer la importancia que tiene la economía del oro en el desarrollo de las regiones a nivel mundial.

La reflexión que quiere dejar este artículo sobre los contratos de explotación con compañías multinacionales además de generar graves impactos ambientales relacionados con la extracción y el procesamiento (para extraer un gramo de oro es necesario consumir hasta 1060 litros de agua), implican una explotación del área por períodos largos (treinta años, en promedio), llevando a la pérdida total del paisaje, de la flora y la fauna, así como la ruptura de los habitantes con su territorio.

Cuando el agua se usa en la minería de oro, el estado de contaminación por sustancias químicas tóxicas (mercurio, cianuro, entre otras) hace inviable su uso para consumo humano, al igual que afecta al suelo y la fauna y flora de la zona. Esta situación es un argumento más que válido para entender la posición de las comunidades directa o indirectamente afectadas, como las del páramo de Santurbán. Conflictos sociales entre empresa y pobladores, quienes se oponen rotundamente a que el páramo y sus límites sigan siendo subastados por el Gobierno colombiano al mejor postor, enmarcan la realidad de un país en el que las autoridades ambientales están limitadas en sus funciones y tienen un margen estrecho de maniobra. Igualmente, las políticas de desarrollo nacional fundamentadas en un crecimiento verde son más un discurso que una realidad.

En los escenarios planteados entran en juego otro actor social que no protesta en contra de las multinacionales y la explotación de oro en los páramos, sino que defiende la minería de oro porque es su única forma de sustento, que han vivido de la minería desde generaciones y no conciben otra forma de trabajo. Asimismo, este sector considera que la llegada de las empresas multinacionales ha perturbado su forma tradicional de vida en el territorio, altera costumbres y rompe vínculos familiares.

La delimitación de la zona de páramo no es suficiente para acabar con el conflicto suscitado por la explotación minera en áreas de ecosistemas estratégicos. En el 2016, la Corte falló a favor de la prohibición total de la minería en los páramos; sin embargo, no consideró las familias que habitaban estas zonas.

El abandono de las zonas mineras tradicionalmente pobres ha marcado la desconfianza y la baja interacción del Gobierno con los habitantes locales de esas zonas, a lo que se suma el problema de las necesidades básicas insatisfechas. Razones por las que en algunos casos las expectativas de las poblaciones son muy altas y superan muchas veces el alcance de los programas de responsabilidad social de las empresas. Algunas de las protestas nacen por la frustración inicial, estimulada por grupos radicales, enemigos de la actividad minera y, en algunos casos, intereses particulares específicos (Cuestas, 2015). 
No debe desconocerse el aporte que las inversiones en minería hacen al desarrollo económico del país, razón suficiente para que el Estado colombiano y las grandes compañías mineras ajusten las políticas y normas jurídicas y garanticen estabilidad de los inversionistas extranjeros; no obstante, ambos actores deben respetar los acuerdos pactados con las comunidades y adelantar las explotaciones mineras dentro de los estándares internacionales sociales, económicos y ambientales, para que así se respeten las necesidades de todos y cada uno de los sectores sociales que forman parte del desarrollo económico del país.

\section{Referencias}

Agence Française de Développement. (2014). Ciudades y Territorios Sostenibles (17a edición). Medellín: AFD.

Ahumada, O. (11 de mayo de 2017). Mineras quieren invertir US\$7600 millones si hay garantías. El Tiempo. Recuperado de http://www.eltiempo.com/economia/sectores/inversion-minerapara-los-proximos-anos-en-colombia-86762

Alcaldía de Vetas. (2016). Nuestro municipio. Información general. Recueprado de http://www.vetas-santander.gov.co/informacion_general.shtml

Alzate, L. (2015). Minería de oro en el marco de la inseguridad normativa, los grupos de interés y las zonas de exclusión. Opinión Jurídica, 14(28), 117-134.

Andrade, G., Rodríguez, M., y Wills, E. (2012). Dilemas Ambientales de la gran minería en Colombia. Revista Javeriana, 148(785), 17-23.

AngloGold Ashanti Colombia. (2013). La Colosa, una oportunidad de oro para el Tolima. Recuperado de http://www.anglogoldashanti.com.co/saladeprensa/Presentaciones/Forms/2015.aspx

AngloGold Ashanti analizará consecuencias tras el "No" de Cajamarca a explotación minera. (27 de marzo de 2017). El País. Recuperado de http://www.elpais.com.co/colombia/anglogoldashanti-analizara-consecuencias-tras-no-de-cajamarca-a-explotacion-minera.html

Buitrago, E. (2012). Entre el agua y el oro: tensiones y reconfiguraciones territoriales en el municipio de Vetas, Santander, Colombia (tesis de pregrado). Departamento de Antropología, Facultad de Ciencias Humanas, Universidad Nacional de Colombia, Bogotá D. C., Colombia.

Cabrera, M., y Fierro, J. (2013). Implicaciones ambientales y sociales del modelo extractivista en Colombia. En L. Garay (dir.), Minería en Colombia, fundamentos para superar el modelo extractivista (pp. 89-123). Bogotá: Contraloría General de la República.

Cambio de reglas disminuye la inversión en minería. (30 de Marzo de 2016). Portafolio. Recuperado de http://www.portafolio.co/economia/gobierno/colombia-cambio-reglas-disminuyeinversiones-mineria-493315

CDMB. (2015). Páramo Santurbán. Recuperado de http://www.cdmb.gov.co/web/sitios-de-interes-ambiental/parque-naturales-regionales/paramo-de-santurban

Centro de Investigación y Educación Popular. (2012). Minería, conflictos sociales y violación de derechos humanos en Colombia. Bogotá D. C.: CINEP.

CEPAL. (2014). Evaluaciones del desempeño ambiental Colombia 2014. [s. d.]: CEPAL-Naciones Unidas. 
Conferencia General de la Organización Internacional del Trabajo. (1989). Convenio 169. Convenio sobre pueblos indigenas y tribales en paises independientes. Recuperado de http://www. corteconstitucional.gov.co/relatoria/CONVENIO\%20169\%20DE\%20LA\%20OIT.\%20 SOBRE\%20PUEBLOS\%20INDIGENAS\%20Y\%20TRIBALES\%20EN\%20PAISES\%20INDEPENDIENTES.php

Contraloría General de la República de Colombia. (9 de febrero de 2017). Minería continúa en páramos de Santurbán y Miraflores. El Espectador. Recuperado de http://www.elespectador. $\mathrm{com} /$ noticias/medio-ambiente/mineria-continua-en-paramos-de-santurban-y-mirafloresarticulo-679064

Corte Constitucional. (8 febrero de 2016). Sentencia C-035 de 1996. [M. P. Gloria Stella Ortiz Delgado]. Expediente D-10864.

Cuestas, D. (2015). Brújula minera: aporte e imagen para revisar. Mundo Minero, 2(16), 26-30.

Duque, M. (24 de Enero de 2011). El caso de Saturbán. Minería en el páramo de Santurbán ¡No viable!. La Razón Pública, pp. 1-6.

Eco Oro minerals Corp. (2017). Sostenibilidad. Comunidad. Recuperado de http://www.eco-oro. $\mathrm{com} / \mathrm{sp} /$ Community.asp

Eco Oro. (2017). Angostura. Recuperado de http://www.eco-oro.com/sp/Angostura.asp

El fracaso de Santurbán. (9 de abril de 2016). Semana Sostenible. Recuperado de http://sostenibilidad.semana.com/medio-ambiente/articulo/santurban-el-fracaso-de-la-delimitacion/34878

Fierro, J. (28 de Marzo de 2011). Minería en los páramos: el agua vale más que el oro. La Razón Pública, pp. 6-11.

Francisco. (2015). Laudato si': sobre el cuidado de la casa común. Roma: Ediciones UC.

García, H. (dir.). (2013). Valoración de los bienes y servicios ambientales provistos por el Páramo de Santurbán.. Bogotá D. C.: Fedesarrollo.

Güiza, L. (2010). Minería de hecho en Colombia. Bogotá D. C.: Defensoría del Pueblo Colombia.

Instituto de Investigación en Recursos Biológicos Alexander von Humboldt. (s. f.). Concepto tecnico pertinente a la delimitación y caracterización del sistema paramuno en el área de la serranía de Santurbán. Concepto técnico. Bogotá: IAvH.

Instituto de Investigación de Recursos Biológicos Alexander von Humboldt. (2014). Guía de trabajo con comunidades de páramos (1ª edición). Bogotá: IAvH.

Instituto de Investigación de Recursos Biológicos Alexander von Humboldt. (2017). Páramos y sistemas de vida: Santurbán. Recuperado de http://www.humboldt.org.co/es/test/item/558paramos-y-sistemas-de-vida-santurban

La comunidad, pieza clave en un proyecto de minería. (25 de mayo de 2017). Portafolio. Recuperado de http://www.portafolio.co/economia/la-comunidad-pieza-clave-en-un-proyectode-mineria-506219

Londoño, V. (6 de mayo de 2013). Colombia no está preparada para la locomotora minera. El Espectador. Recuperado de https://www.elespectador.com/noticias/medio-ambiente/colombia-no-esta-preparada-locomotora-minera-articulo-420422 
López, I., y Díaz, M. (2009). Gestión ambiental en el páramo de Santurbán, distrito minero California-Vetas (tesis de pregrado). Escuela de Economía y Administración, Universidad Industrial de Santander, Bucaramanga, Colombia.

Mineros artesanales ganan pleito a multinacional Gran Colombia Gold. (28 de febrero de 2017). Semana. Recuperado de http://www.semana.com/nacion/articulo/corte-falla-a-favor-demineros-artesanales-por-cerro-en-marmato/517067

Ministerio de Ambiente y Desarrollo Sostenible y Programa de las Naciones Unidas para el Desarrollo. (2014). V Informe nacional de biodiversidad de Colombia ante el Convenio de Diversidad Biológica. Bogotá D. C.: MinAmbiente, PNUD.

Monsalve, M. (24 de Marzo de 2017). Proyecto minero La Colosa: ¿sí o no?. El Espectador. Recuperado de http://www.elespectador.com/noticias/medio-ambiente/proyecto-minero-lacolosa-si-o-no-articulo-686011

Monsalve, M. (18 de Abril de 2017). Nuevo proyecto minero se avecina en Santurbán. El Espectador. Recuperado de http://www.elespectador.com/noticias/medio-ambiente/nuevo-proyecto-minero-se-avecina-en-santurban-articulo-689829

Morales, M. (2007). Atlas de páramos de Colombia. Bogotá D. C.: Instituto de Investigación de Recursos Biológicos Alexander von Humboldt.

Morales, M. (2007). Atlas de páramos de Colombia. Bogotá D. C.: Instituto de Investigación de Recursos Biológicos Alexander von Humboldt.

Mojica, Y. (2017). De la actividad humana a los ecosistemas; el oro o el agua, caso del Páramo de Santurbán (tesis de especialización). Especialización en Gestión Ambiental, Fundación Universidad de América, Bogotá, Colombia.

Red Eagle Exploration. (2017). California gold project. Recuperado de http://www.redeaglex.com/ projects/california-gold/details/

Reuters. (25 de abril de 2017). Buscan salida para que regiones en Colombia no veten la minería. El Tiempo. Recuperado de http://www.eltiempo.com/economia/sectores/gobierno-preparaproyecto-de-ley-para-evitar-veto-a-la-mineria-en-regiones-81256

Saade, H. (2014). Buenas prácticas que favorezcan una minería sustentable. La problemática en torno a los pasivos ambientales mineros en Australia, el Canadá, Chile, Colombia, los Estados Unidos, México y el Perú (serie Macroeconomía del Desarrollo n. ${ }^{\circ}$ 157). Santiago de Chile: Naciones Unidas.

Sarmiento, C. (2014). Aportes a la delimitación del páramo mediante la identificación de los límites inferiores del ecosistema a escala 1:25000 y análisis del sistema social asociado al territorio: complejo de páramos jurisdicciones-Santurbán-Berlín. Bogotá D. C.: Colombia: IAvH.

Silva, S. (16 de Enero de 2014). La minería en Colombia: la maldición de los recursos naturales. El Tiempo. Recuperado el 16 de Febrero de 2017, de http://www.eltiempo.com/archivo/ documento/CMS-13366835

Sociedad Minera de Santander. (2017). Nuestro proyecto. Recuperado de http://minesa.com/nuestro-proyecto/

Sociedad Nacional de Minería, Petróleo y Energía. (2017). Encuesta Fraser Institute. Recuperado de www.snmpe.org.pe/minería/encuestas-frazer-institute.html

World Economic Forum. (2013). Iniciativa para el desarrollo de la minería responsable. Ginebra: WEF. 